\title{
Analysis of Factors Related To Head MRI Changes In Neonatal Hyperbilirubinemia And Effect On Neurodevelopmental Outcomes.
}

\section{Russel Takam}

First Affiliated Hospital of Dalian Medical University

\section{Ma Shuang}

First Affiliated Hospital of Dalian Medical University

\section{Xiu Bao}

First Affiliated Hospital of Dalian Medical University

Cong Tian

First Affiliated Hospital of Dalian Medical University

Ji Hong ( $\nabla$ jihongsdq@126.com )

First Affiliated Hospital of Dalian Medical University

\section{Research Article}

Keywords: Hyperbilirubinemia, risk factors, head imaging (MRI, DWI), neurodevelopmental outcomes

Posted Date: June 21st, 2021

DOI: https://doi.org/10.21203/rs.3.rs-618588/v1

License: (c) (1) This work is licensed under a Creative Commons Attribution 4.0 International License. Read Full License 


\section{Abstract}

\section{Background and Objective}

This study aims to detect how hyperbilirubinemia affects cerebral structures by imagery (MRI) to prevent irreversible future brain damage.

\section{Research Design and Methods}

In this retrospective study, 50 infants of 35 weeks gestation or more with hyperbilirubinemia were assigned to two groups based on abnormal or normal head imaging (MRI). The primary outcomes included peak bilirubin levels according to socio-demographic factors and how these levels influence MRI.

The secondary outcome was neurodevelopment at 1, 3, 6, 9 and 12 months for the imaging changes versus the normal imaging groups assessed by a combined formulaire based on the CDC's developmental milestones, the Denver II Developmental Screening Test (DDST), the Hammersmith infant neurological exam, and auditory brainstem response (ABR) by investigators.

\section{Results}

Peak serum bilirubin levels (TSB) in the group with MRI changes, defined as bilaterally symmetrical signal intensity on T1- weighted imaging in the globus pallidus GP, was significantly higher than those in the group without MRI changes $(342.5 \pm 47.6 \mu \mathrm{mol} / \mathrm{L}$ vs. $284.3 \pm 46.3 \mu \mathrm{mol} / \mathrm{L}), \mathrm{p}=0.000$. Odds ratios when observing TSB values with $342 \mu \mathrm{mol} / \mathrm{L}$ as cut-off, showed that participants with TSB $\geq 342 \mu \mathrm{mol} / \mathrm{L}$ were 12.4 times more likely of presenting with abnormal MR imaging (OR=12.4, 95\% $\mathrm{Cl} 2.191-70.672)$. In addition, a cross-tab comparison between MRI and milestones depicts MRI as having a $66.7 \% \varangle 33.3 \%$ sensitivity and specificity while $12.5 \% \bigotimes 97.1 \%$ PPV (positive predictive value) and NPV (negative predictive values) respectively for milestone attainment. No relationship was found between abnormal outcomes and abnormal MRI.

\section{Conclusions}

A significant relationship between high bilirubin levels and head imaging (MRI) was observed, but these changes in imaging could not significantly predict neurodevelopmental outcomes.

\section{Introduction}

Neonatal hyperbilirubinemia (NHB) is a common occurrence affecting about $60 \%$ of term and $80 \%$ of preterm infants $^{1,2}$. In 1904, Schmorl described yellow staining of the basal ganglia in postmortem findings of infants with neonatal jaundice ${ }^{3,4}$. It refers to increased bilirubin levels seen in neonates with a variable clinical outcome from reversible acute bilirubin encephalopathy (ABE) to irreversible kernicterus ${ }^{5}$. $10 \%$ of term and $25 \%$ of late preterm deliveries will undergo phototherapy to avoid acute and chronic 
bilirubin encephalopathy ${ }^{6}$. The cost of caring for a patient with kernicterus over a lifetime is estimated at around \$USD 900000 while the estimated cost to prevent a single case of kernicterus with universal total serum bilirubin and/or transcutaneous bilirubin screening is between \$USD 5.7 and 9.2 million ${ }^{7}$, making neonatal jaundice a health concern.

Magnetic resonance imaging (MRI) is used as the imaging of choice for examining structural changes at the level of the basal ganglia and subthalamus, the two most affected cortical areas in encephalopathy ${ }^{8}$. The most widely accepted changes show abnormally increased signal intensity on T1-weighted imaging in these areas. Few studies have been used to show the structural changes observed using DWI in neonatal hyperbilirubinemia ${ }^{9}$.

Can early detection of central nervous system damage in children with hyperbilirubinemia be detected to guide early intervention and reduce permanent damage and sequelae? Can Magnetic resonance imaging (MRI), be used as an indicator for predicting brain damage and late neurodevelopment? To answer these questions, we conducted retrospective cohort studies in 50 children with hyperbilirubinemia.

\section{Patients And Methods}

Overall 50 participants ( 21 males, 29 females) with TSB $\geq 210 \mu \mathrm{mol} / \mathrm{L}$ were included in the study after being born or referred at the first affiliated hospital of Dalian Medical University between December 2019 and February 2021. A gestational age (GA) of at least 35 weeks, a postnatal age less than 2 weeks were criteria for inclusion. Others were clinically observable jaundice with TSB $\geq 210 \mu \mathrm{mol} / \mathrm{L}$ on the first day of birth or on subsequent days. They were divided according to their TSB levels as follows : low $\leq$ $256 \mu \mathrm{mol} / \mathrm{L}$, moderate $256-340 \mu \mathrm{mol} / \mathrm{L}$ and high $>340 \mu \mathrm{mol} / \mathrm{L}$. Infants were divided into preterm $(<37$ weeks gestational age, GA), early-term (37-38 weeks GA), and full-term ( $>38$ weeks $G A)$. In addition, participants with signs of acute or chronic bilirubin encephalopathy (ABE,CBE) manifested as lethargy, shill cry, hypo/hypertonia, seizures, auditory or occular abnormalities were also included. Congenital anomaly, confirmed infections,or metabolic derangement, intracranial hemorrhage or injury, and those who did not give their accord to do MRI, DWI sequencing or ABR were excluded. All participants were treated with phototherapy.

Anthropometric measurements including gender, birth weight, head circumference of each participant was recorded as predictors. Birth weight was classified using AAP criteria as low birth weight LBW < 2500g, normal birth weight NBW 2500-4000g and high birth weight HBW $>4000 \mathrm{~g}$. In addition, the method of delivery, gestational age at delivery, feeding methods were equally recorded. Etiologies for hyperbilirubinemia were obtained if found.

MRI was performed with a 1.5 Tesla (T) clinical MR unit (Magnetom Sonata; Siemens, Erlangen, Germany), with a standard infant head coil after administration of $5 \%$ chloral hydrate $0.5 \mathrm{ml} / \mathrm{kg}$ per os for sedation. Transverse and axial planes were used to obtained with T1- weighted spin echo images. Fluid Attenuation recovery (FLAIR) and diffusion-weighted imaging (DWI) were equally obtained. Apparent 
diffusion coefficients (ADC) were rcorreletaed with DWI to determine fluid restriction, thereby hyperintensity. MRI scanning documented the following findings as abnormal: a) High signal intensity SI in the GP and basal ganglia b) white matter SI with extent and location of lesion and comparing with SI of the basal ganglia.

Universal screening for hearing loss or dysfunction was done in all participants who had their audition tested using auditory brainstem evoked response (ABER) and audiometry (in situ and autoacoustic emission), with abnormal results recorded.

A questionnaire based on attainment of milestones at 1, 3, 6, 9 and 12 months respectively was designed for the purpose of this study, based on Hammersmith infant neurologic exam ${ }^{10}$, the CDC (Center of Disease Control) developmental milestones ${ }^{11}$, and the Denver II Developmental Screening Test (DDST) ${ }^{12}$ and was used for follow-up to access development. DDST includes a series of age specific questions and an evaluation chart to characterize development 4 outcomes in terms of social (emotional), language (communication), and both gross and motor skills. On this chart, questions and observation were recorded as percentages, according to the patients age in months. According to the guideline, a patient was classified as having a delay when failing on an item matching $90 \%$ the age. This delay was then assessed for one of each of the four subgroups. If there are two or more delays, the result is considered abnormal. After obtaining a final score, patients results in subgroups were classified as normal or abnormal. Baseline characteristics in were recorded in Table 1 below. 
Table 1

Baseline characteristics of participants in our study.

\begin{tabular}{|c|c|c|}
\hline Variables & Baseline value $(n=50)$ & Mean \pm SD \\
\hline Gender: Male & $21(42 \%)$ & \\
\hline Female & $29(58 \%)$ & \\
\hline Birth weight: LBW $(<2500 \mathrm{~g})$ & $2(4 \%)$ & $2130.0 \pm 14.1$ \\
\hline NBW (2500-4000g) & $42(84 \%)$ & $3297.0 \pm 315.7$ \\
\hline HBW (> 4000g) & $6(12 \%)$ & $4215.0 \pm 141.7$ \\
\hline GA (weeks): Preterm (<37) & $2(4 \%)$ & $35.5 \pm 0.7$ \\
\hline Early term (37-38) & $25(50 \%)$ & $37.5 \pm 0.5$ \\
\hline Full-term (> 38) & $23(46 \%)$ & $39.3 \pm 0.5$ \\
\hline Peak TSB $(\mu \mathrm{mol} / \mathrm{L})$ : Low TSB $(<256)$ & $10(20 \%)$ & $225.6 \pm 23.9$ \\
\hline Moderate TSB (256-340) & $31(62 \%)$ & $304.7 \pm 21.2$ \\
\hline High TSB (>340) & $9(18 \%)$ & $382.9 \pm 26.2$ \\
\hline Nutrition: Breastfeeding & $22(44 \%)$ & \\
\hline Formula & $2(4 \%)$ & \\
\hline Mixed & $26(52 \%)$ & \\
\hline Delivery: Vaginal & $28(56 \%)$ & \\
\hline Cesarean & $22(44 \%)$ & \\
\hline Therapy: P only & $37(74 \%)$ & \\
\hline$P+A$ & $7(14 \%)$ & \\
\hline$P+$ Alb & $2(4 \%)$ & \\
\hline$P+A l b+I V l g$ & $1(2 \%)$ & \\
\hline$P+A+A l b+I V I G$ & $2(4 \%)$ & \\
\hline$P+M+P h$ & $1(2 \%)$ & \\
\hline Etiology: Idiopathic & $30(60 \%)$ & \\
\hline Infections & $8(16 \%)$ & \\
\hline ABO incompatibility & $6(12 \%)$ & \\
\hline Polycythemia & $2(4 \%)$ & \\
\hline Intracranial bleeding & $4(8 \%)$ & \\
\hline
\end{tabular}




\begin{tabular}{|lll|}
\hline Variables & Baseline value $(\mathbf{n}=50)$ & Mean \pm SD \\
\hline Age (days) & & $3.3 \pm 2.1$ \\
\hline HC $(\mathrm{cm})$ & & $33.8 \pm 1.4$ \\
\hline Tc $(\mathrm{mg} / \mathrm{dL})$ & & $14.6 \pm 3.5$ \\
\hline Albumin (g/L) & & $34.2 \pm 3.6$ \\
\hline Jaundice observation from birth (days): & & $2.3 \pm 1.1$ \\
\hline Days from admission to imaging: & & $3.4 . \pm 1.5$ \\
\hline Maternal age (years): & & $32.4 \pm 3.4$ \\
\hline Gravida: Primipara & $22(44 \%)$ & \\
\hline Multipara & $28(56 \%)$ & \\
\hline Antepartum pathology: None & $30(60 \%)$ & \\
\hline Hypertension only & $3(6 \%)$ & \\
\hline Diabetes only & $5(10 \%)$ & \\
\hline Hypertension and diabetes & $4(8 \%)$ & \\
\hline Thyroid disorders & $2(4 \%)$ & \\
\hline Others & $6(12 \%)$ & \\
\hline Maternal blood group A+ & $13(26 \%)$ & \\
\hline B+ & $15(30 \%)$ & \\
\hline AB+ & $5(10 \%)$ & \\
\hline 0+ & $17(34 \%)$ & \\
\hline ABR Normal & $45(90 \%)$ & \\
\hline Abnormal & $5(10 \%)$ & \\
\hline MR imaging Normal & $34(68 \%)$ & \\
\hline Abnormal & $16(32 \%)$ & \\
\hline Milestones Normal & & \\
\hline Abnormal & & \\
\hline
\end{tabular}

Abbreviations: LBW- low birth weight, NBW -normal birth weight, HBW -high birth weight, GA - gestational age, HC - Head circumference, Tc - Transcutaneous bilirubin, P- phototherapy, P+A - phototherapy and antibiotics, P+Alb - phototherapy and albumin, P+Alb+IVlg - phototherapy, albumin and intravenous 
immunoglobulins, $\mathrm{P}+\mathrm{M}+\mathrm{Ph}$ - phototherapy, mannitol and phenobarbital, others include HELLP syndrome, APS, thyroiditis and vaginitis.

Informed parental consent was obtained from the guardians of all participants in the study. Our methodology was carried out in accordance with relevant guidelines and regulations. Our study was approved by the ethical committee of the First Affiliated Hopital of Dalian Medical University.

Partaking to statistical analysis, mean, standard deviation, and minimum and maximum values were referred to as continuous variables, and the categorical variables were expressed as numbers and percentages. The Mann-Whitney $U$ test was used in the comparison of continuous variables. Moreover, the student t-test was used in the comparison of MRI changes and normal groups. In addition, binary logistic regression analysis was performed to separately access hyperbilirubinemia, changes in imaging, and their relationship with milestone attainment. The statistical analysis was performed with SPSS software (version 25.0). The probability level of less than 0.05 was considered significant.

\section{Results}

\subsection{Neonatal and maternal findings.}

Our study comprised of 50 neonates; 21 boys and 29 girls, admitted with a mean age of $3.3 \pm 2.1$ days and who presented in our department with a mean time of $2.3 \pm 1.1$ days from birth to clinical observation of jaundice from guardians. The mean weight of admission was $3360.5 \pm 489.9 \mathrm{~g}$ with a mean gestational age of $38.2 \pm 1.2$ weeks, and a head circumference of $33.8 \pm 1.4 \mathrm{~cm}$. Baseline characteristics of participants were recorded and TSB values were recorded in Table 2. None of the infants on admission demonstrated abnormal neurological findings of ABE (lethargy, drowsiness, high-pitched cry or deficient motor tones) nor CBE.

Maternal factors such as age, gravida number, blood group, and antepartum pathologies were collected and compared between groups. There was a statistically significant difference between antenatal pathologies in the group of infants presenting with MRI imaging compared to those without. Infants with mothers with both gestational hypertension (eclampsia, others) and gestational diabetes had higher bilirubin levels $(322.9 \pm 48.5 \mu \mathrm{mol} / \mathrm{L})$ compared to those with other pathologies. In addition, the mean maternal age of infants presenting with changes on imaging is higher than those without changes.

\section{Table 2: Summary table of average peak TSB values with socio-demographic factors of participants.}




\begin{tabular}{|c|c|c|c|}
\hline Factors & $\begin{array}{l}\text { Peak TSB in } \\
\mu \mathrm{mol}\end{array}$ & $\begin{array}{l}\text { Interquartile range } \\
\text { IQR }\end{array}$ & $\begin{array}{l}\mathrm{P} \text { - } \\
\text { value }\end{array}$ \\
\hline Males & $325.8 \pm 43.9$ & 58.5 & \\
\hline Females & $286.4 \pm 54.8$ & 67.5 & 0.009 \\
\hline LBW & $258.9 \pm 28.9$ & & \\
\hline NBW & $305.4 \pm 52.8$ & 58.8 & \\
\hline HBW & $300.2 \pm 66.7$ & 86.2 & 0.494 \\
\hline Preterm & $282.0 \pm 3.7$ & & \\
\hline Early Term & $303.2 \pm 55.7$ & 49.5 & \\
\hline Full-Term & $304.5 \pm 54.9$ & 70.5 & 0.856 \\
\hline Breastfeeding & $310.7 \pm 59.3$ & 84.6 & \\
\hline Mixed nutrition & $300.4 \pm 46.8$ & & \\
\hline Formula & $250.5 \pm 77.8$ & 46.8 & 0.304 \\
\hline Etiology: Idiopathic & $306.1 \pm 56.5$ & 72.7 & \\
\hline Probable infections & $307.3 \pm 58.5$ & 67.2 & \\
\hline ABO hemolysis & $296.2 \pm 54.4$ & 73.4 & \\
\hline Polycythemia & $276.0 \pm 81.7$ & & \\
\hline Intracranial hemorrhage & $294.4 \pm 19.5$ & 37.2 & 0.938 \\
\hline Phototherapy only & $296.3 \pm 51.8$ & 68.6 & \\
\hline Phototherapy and antibiotics & $307.6 \pm 63.2$ & 81.6 & \\
\hline Phototherapy and albumin & $388.1 \pm 59.2$ & & \\
\hline Phototherapy, albumin and IVIG & $314.8 \pm 15.8$ & & 0.320 \\
\hline Maternal age: Less than 30 years & $332.3 \pm 47.5$ & 80.8 & \\
\hline Maternal age: 30 years and above & $296.5 \pm 53.4$ & 55.8 & 0.070 \\
\hline Primipara & $299.1 \pm 39.9$ & 45.0 & \\
\hline Multipara & $306.0 \pm 63.1$ & 84.3 & \\
\hline Vaginal delivery & $317.9 \pm 49.3$ & 56.3 & \\
\hline Cesarean delivery & $283.8 \pm 54.2$ & 77.3 & \\
\hline No antepartum pathology & $310.8 \pm 58.1$ & 64.9 & \\
\hline Maternal hypertension & $\begin{array}{l}305.3 \pm 13.1 \\
\text { age } 8 / 20\end{array}$ & & \\
\hline
\end{tabular}




\begin{tabular}{llll}
\hline Maternal diabetes & $249.3 \pm 59.1$ & 97.9 & \\
\hline Maternal hypertension and diabetes & $322.9 \pm 48.5$ & 93.1 & 0.270 \\
\hline Maternal thyroid disorders & $307.3 \pm 2.5$ & & \\
\hline Other antepartum pathologies & $292.4 \pm 27.9$ & 43.3 & 67.9 \\
\hline A+ & $335.9 \pm 38.9$ & 45.9 & 0.038 \\
\hline B+ & $296.1 \pm 54.1$ & 95.5 & \\
\hline AB+ & $312.0 \pm 57.2$ & 82.4 & 0.000 \\
\hline O+ & $281.0 \pm 53.6$ & 81.1 & 0.695 \\
\hline Abnormal MRI & $342.5 \pm 47.6$ & & \\
\hline Normal MRI & $284.3 \pm 46.3$ & 72.2 & 0.561 \\
\hline Abnormal DWI & $314.9 \pm 19.5$ & & 0.975 \\
\hline Normal DWI & $302.2 \pm 55.3$ & 60.8 & \\
\hline Normal ABR & $302.9 \pm 50.0$ & 54.3 & 0.552 \\
\hline Abnormal ABR & $303.7 \pm 88.9$ & 177.6 & \\
\hline Normal Milestones & $304.1 \pm 54.6$ & & \\
\hline Abnormal Milestones & $284.8 \pm 40.3$ & & \\
\hline Albumin $<35 \mathrm{~g} / \mathrm{L}$ & $289.3 \pm 47.2$ & 43.3 & 65.0 \\
\hline Albumin $\geq 35 \mathrm{~g} / \mathrm{L}$ & $320.3 \pm 57.6$ & 58.9 & \\
\hline Jaundice observation on day 1 & $293.9 \pm 49.9$ & 62.5 & \\
\hline Jaundice observation $>$ day 1 & $305.2 \pm 55.0$ & & \\
\hline
\end{tabular}

\subsection{MRI scans}

MRI scans were performed in all 50 infants. Axial T1 MRI signal intensity values of the left and right basal ganglia were measured and recorded. Symmetrical hyperintensity was mostly observed in the globus pallidus on T1-weighted imaging in 16 participants while none showed increased intensity on T2weighted imaging. DWI sequences showed no abnormality in any participant. All but two infants did an MRI follow-up after 3 to 6 months with only one having persistent hyperintensity in the basal ganglia.These signal values were compared to peak TSB levels, ABR and milestone attainment and pearson correlation were obtained to evaluate the relationship between the variables. Signal values of the left and right basal ganglia are significantly higher when compared to various levels of peak TSB (right Pvalue $=0.005$, left P-value $=0.0040$ ). Further extrapolation of cut-off values to determine the sensitivity 
and specificity of MR imaging using an Receiver operator characteristic, ROC curve shows a significant area $=0.782$, with a peak TSB value of $310.5 \mu \mathrm{mol} / \mathrm{L}$ having true and false positive values of $62.5 \%$ and $35.3 \%$ on MR imaging. Average peak TSB values of participants in the abnormal MRI group was $342.5 \pm 47.6 \mu \mathrm{mol} / \mathrm{L}$ whereas average peak TSB values in the group with normal imaging was $284.3 \pm 46.3 \mu \mathrm{mol} / \mathrm{L}$ and there was a significant difference between both groups $(P=0.000)$, as seen in Table 3 below.

Table 3: Comparison of demographic and biologic data of neonates with hyperbilirubinemia between those with normal and abnormal imaging. 


\begin{tabular}{|c|c|c|c|}
\hline Variables & $\begin{array}{l}\text { Imaging changes } \\
\text { (16) }\end{array}$ & No imaging changes (34) & P-value \\
\hline Male (\%) & $8(50.0)$ & 13(38.2) & \\
\hline Female (\%) & $8(50.0)$ & $21(61.8)$ & 0.543 \\
\hline Gestational age (weeks) & $38.0 \pm 1.4$ & $38.4 \pm 1.1$ & 0.325 \\
\hline Age (days) & $4.2 \pm 2.2$ & $2.9 \pm 1.9$ & 0.034 \\
\hline Low peak TSB $(\mu \mathrm{mol} /)$ & $0.0 \pm 0.0$ & $225.6 \pm 23.9$ & \\
\hline Moderate peak TSB $(\mu \mathrm{mol} / \mathrm{L})$ & $305.7 \pm 15.9$ & $304.3 \pm 23.3$ & \\
\hline High peak TSB ( $\mu \mathrm{mol} / \mathrm{L})$ & $389.9 \pm 25.5$ & $358.6 \pm 5.6$ & 0.000 \\
\hline Preterm (weeks) & $35.0 \pm 0.0$ & $36.0 \pm 0.0$ & \\
\hline Early term (weeks) & $37.3 \pm 0.5$ & $37.6 \pm 0.5$ & \\
\hline Full term (weeks) & $39.3 \pm 0.5$ & $39.3 \pm 0.5$ & 0.708 \\
\hline LBW (grams) & $2120 \pm 0.0$ & $2140 \pm 0.0$ & \\
\hline NBW (grams) & $3306.4 \pm 330.0$ & $3292.3 \pm 314.3$ & \\
\hline HBW (grams) & $4100.0 \pm 0.0$ & $4238.0 \pm 145.3$ & 0.332 \\
\hline Transcutaneous bilirubin (mg/dL) & $15.7 \pm 4.3$ & $14.0 \pm 3.0$ & 0.110 \\
\hline Albumin $(\mathrm{g} / \mathrm{L})$ & $34.9 \pm 3.3$ & $33.9 \pm 3.6$ & 0.329 \\
\hline Head circumference $(\mathrm{cm})$ & $33.4 \pm 1.4$ & $33.9 \pm 1.4$ & 0.394 \\
\hline Jaundice observation on day 1 (\%) & $2(12.5 \%)$ & $8(23.5 \%)$ & \\
\hline $\begin{array}{l}\text { Jaundice observation from day } 2 \\
\text { (\%) }\end{array}$ & $14(87.5 \%)$ & $26(76.5 \%)$ & 0.468 \\
\hline Breastfeeding & $8(50,0 \%)$ & $14(41.2 \%)$ & \\
\hline Mixed & $7(43.8 \%)$ & $19(55.9 \%)$ & \\
\hline Formula & $1(6.3 \%)$ & $1(2.9 \%)$ & 0.489 \\
\hline Abnormal milestones & $2(12.5 \%)$ & $1(2.9 \%)$ & \\
\hline Normal milestones & $14(87.5 \%)$ & $33(97.1 \%)$ & 0.237 \\
\hline Right basal ganglia signal intensity & 580.65 & 450.36 & 0.001 \\
\hline Left basal ganglia signal intensity & 582.20 & 452.44 & 0.001 \\
\hline Etiologies & & & 0.565 \\
\hline Therapies & & & 0.087 \\
\hline
\end{tabular}




\subsection{Follow-up for milestones and audition.}

Using the evaluation forms based on DDST and CDC milestone attainment, neurodevelopment was evaluated in terms of language, social, fine and gross motor skills. There was no significant difference between MRI changes and normal MRI groups when evaluating milestones $(p=0.237)$. 3 participants ( 2 males, 1 female) had abnormal outcomes during follow-up as seen in Table 4.1 male showed delayed milestones at 3 months and the last male showed a delay at 6 months. In addition, a cross-tab comparison between MRI and milestones depicts MRI as having a $66.7 \% \otimes 70.2 \%$ sensitivity and specificity while $12.5 \% \bigotimes 97.1 \%$ PPV (positive predictive value) and NPV (negative predictive values) respectively for milestone attainment.

Table 4

Summary of Participants with abnormal outcomes.

\begin{tabular}{|lllllll|}
\hline Gender & Age & MRI & Neuro Exam & CDC & ABR & DDST \\
\hline Male & 3 months & Normal & Normal & Abnormal & Normal & Abnormal \\
Male & 6 months & Abnormal & Abnormal & Normal & Normal & Abnormal \\
\hline Female & 9 months & Abnormal & Abnormal & Abnormal & Abnormal & Abnormal \\
\hline
\end{tabular}

It is interesting to note that a 2-day old female infant who had MRI changes (bilateral symmetrical lentiform increased intensity) in Figure 1, had the second lowest albumin level among the participants $(31.8 \mathrm{~g} / \mathrm{L})$, with moderate peak TSB levels $(305.5 \mu \mathrm{mol} / \mathrm{L})$, showed a left ear abnormal ABR and showed delayed milestone attainment at 9 months of age, whereas she showed normal attainment at 1, 3 and 6 months of age. Compared to her age group at 9 months, she scored she showed delays in 3 out of 4 subcategories.

All neonates participating in the study were tested for audition after admission in the neonatology ward. Mean peak TSB values for normal and abnormal milestone attainment were $304.1 \pm 54.6 \mu \mathrm{mol} / \mathrm{L}$ and $284.8 \pm 40.3 \mu \mathrm{mol} / \mathrm{L}$ respectively while peak mean TSB values for normal ABR and abnormal ABR were $302.9 \pm 50.0 \mu \mathrm{mol} / \mathrm{L}$ and $303.7 \pm 88.9 \mu \mathrm{mol} / \mathrm{L}$. 3 neonates ( 2 males, 1 female) showed abnormalities on follow-up.

In addition, a cross-tab comparison between MRI and milestones depicts MRI as having a $66.7 \%$ and $33.3 \%$ sensitivity and specificity In addition, a cross-tab comparison between MRI and milestones depicts MRI as having a $66.7 \% \varangle 33.3 \%$ sensitivity and specificity while $12.5 \% \varangle 97.1 \%$ PPV and NPV respectively for milestone attainment.

Direct logistic regression was employed to assess the impact of several demographic and clinical factors on the likelihood that infants with hyperbilirubinemia will present with abnormal changes on imaging. From our results obtained in Table 5 below, univariate analysis depicted peak TSB accounting for the greatest variance in abnormal MRI at $26.3 \%$, followed by days in observing jaundice in participants (9.5\%), age of participants (8.4\%), and maternal gestational pathology $(7.4 \%)$. 
Table 5

Associated risk factors for neonates with hyperbilirubinemia on having abnormal MRI.

\begin{tabular}{|llll|}
\hline Variables & RR $(95 \%$ Cl) & p-value & $\mathbf{R}^{2}$ \\
\hline Gender & $1.615(0.487,5.361)$ & 0.443 & 0.012 \\
\hline Pregnancy number & $0.802(0.455,1.413)$ & 0.445 & 0.012 \\
\hline Peak TSB & $0.971(0.953,0.990)$ & 0.002 & 0.263 \\
\hline Age of participant & $0.730(0.532,1.003)$ & 0.005 & 0.084 \\
\hline Albumin & $0.916(0.770,1.090)$ & 0.323 & 0.020 \\
\hline Delivery type & $0.700(0.212,2.311)$ & 0.558 & 0.007 \\
\hline Feeding type & $1.246(0.667,2.292)$ & 0.480 & 0.010 \\
\hline Maternal ABO & $1.635(0.956,2.794)$ & 0.072 & 0.068 \\
\hline Transcutaneous bilirubin & $0.864(0.721,1.036)$ & 0.114 & 0.052 \\
\hline Gestational pathology & $0.515(0.317,0.836)$ & 0.007 & 0.074 \\
\hline Gestational age & $1.301(0.774,2.187)$ & 0.320 & 0.020 \\
\hline Birth weight & $1.001(0.999,1.002)$ & 0.435 & 0.012 \\
\hline Jaundice observation from birth & $0.274(0.103,0.731)$ & 0.010 & 0.095 \\
\hline Head circumference & $1.329(0.842,2.098)$ & 0.214 & 0.032 \\
\hline Maternal age & $0.955(0.799,1.141)$ & 0.613 & 0.005 \\
\hline
\end{tabular}

\section{Discussion}

We present clinical and neuroimaging findings in 50 infants with hyperbilirubinemia of different birth weights, gestational age and maternal factors and their neurodevelopmental outcomes. Relationship between TSB, ABE and long-term outcome has been evaluated in previous studies with differing results. A Zimabawean study showed that maximum TSB levels and Bayley scales of infant development scores at 1 year correlated significantly ${ }^{13}$. Newman et al. evaluating infants with maximum TSB levels $\geq 30 \mathrm{mg} / \mathrm{dl}$, showed no adverse outcomes at 18 months and 5 years of age ${ }^{14}$ meanwhile Katar showed subsequent adverse outcomes when evaluating babies with TSB levels greater than $30 \mathrm{mg} / \mathrm{dl}^{15}$.

In our study, we were able to show a consistent relationship between hyperbilirubinemia and MRI changes manifested as bilateral hyperintensity of the GP on T1WI, but a significant correlation between these changes and neurodevelopmental outcomes could not be established with certainty. 
Neonatal jaundice is a chronic worldwide problem and a major cause of morbidity especially in developing countries ${ }^{16-18}$. Bilirubin encephalopathy is not uncommon in China, accounting for about $4.8 \%$ of neonatal hyperlirubinemia. Neonatal hyperbilirubinemia has been found to have an association with development outcomes as it is well known that chronic bilirubin encephalopathy (kernicterus) may lead to long-term neurological and physical deficits ${ }^{8,19-21}$.

Findings from our study showed that neonates with hyperbilirubinemia who have abnormal MR imaging had an association with their gestational ages, birth weights, albumin levels, peak TSB levels, maternal pathology which may have an effect on the neurodevelopment outcome of these neonates.

In the present retrospective cohort, it was observed that the mean gestational age of infants with hyperbilirubinemia which presented with high signal intensity on MR imaging was lower compared to those without changes in imaging. A lengthier change process in dynamic properties and mitochondrial changes has been observed in preterm infants, especially extremely premature ones and this may explain the abnormal image scans preceding the normal ones ${ }^{22}$. In addition, myelination may be a factor causing high signal intensity in preterm populations which may be seen falsely as abnormal imaging due to high bilirubin levels ${ }^{23}$. Our study also supports a higher risk of MRI changes in newborns with low gestational age.

Birth weight is another risk factor for hyperbilirubinemia. Birth weight and prematurity work in tandem as a low gestational age neonate will most likely have a low birth weight after delivery. A study by Woodward demonstrated that low-weight preterm infants with mild to moderate white matter abnormality on MRI had delays by 4 years of age ${ }^{24}$. These studies were done in preterm infants hence the delay in language development could not be ascertained to be due to prematurity, hyperbilirubinemia, or both. Findings from our study showed that neonates who presented with jaundice had lower mean weights in the group with MRI changes compared to those without MRI changes. The difference though was not statistically significant $(p=0.332)$. Contrary to their findings, our cohort showed a significant difference in peak TSB levels between groups, with the TSB levels of participants with MRI changes significantly higher than those without $(p=0.000)$.

It is known that hyperbilirubinemia affects more boys than girls ${ }^{25}$. A study showed that male neonates with a TSB $>340 \mu \mathrm{mol} / \mathrm{L}$ had an increased risk of having an IQ $<85$ on follow-up at 17 years with affected cognition and physical performance ${ }^{26}$. In our study, gender was shown to be statistically different in both groups in term of peak bilirubin levels and MRI changes $(p=0.09)$. Although there were 21 males compared to 28 females, males had significantly higher TSB levels than females $(325.8 \pm 43.9 \mu \mathrm{mol} / \mathrm{L}$ vs $286.4 \pm 54.8 \mu \mathrm{mol} / \mathrm{L})$ respectively.

Auditory neural pathways are highly sensitive to bilirubin-induced toxicity especially in preterm infants who are at a higher risk of this toxicity ${ }^{6,27}$. ABR may predict sensory neural hearing loss with rising TSB levels, but predictive value of $A B R$ to determine neurodevelopmental outcome is not clear. Infants born at $\leq 36$ weeks gestational age with a mean peak TSB of $12 \mathrm{mg} / \mathrm{dL}$ was a significant predictor for hearing 
loss $^{28}$. In our study, 3 out of 16 patients with abnormal MR imaging had an abnormal audio brainstem response (ABR). It is worth mentioning that among these 3 participants, only one went on to show a delayed attainment of milestones at 9 months of age after previously having normal milestones at 1,3 , and 6 months of age (Figure 1). Audiologic follow-up of patients showed normal ABR examinations. This concords with previous findings which show that auditory impairment due to hyperbilirubinemia is reversible. In addition none of the participants with abnormal ABR was preterm nor had birth weights less than $3500 \mathrm{~g}$. We can therefore ascertain that abnormal ABR results was primarily due to hyperbilirubinemia.

Maternal factors such as delivery methods, age, and antepartum pathology can be risk factors for neonatal hyperbilirubinemia. In our study, it was shown that mothers with hypertension and diabetes with other factors had infants with higher mean bilirubin levels and had significant changes on imaging compared to mothers of infants without MRI changes $(p=0.047)$. Our study showed there were more mothers of A+ blood groups in the MRI change group compared to the group without change. Multipara deliveries were associated with infants having higher TSB levels than primipara deliveries although the difference was not significant $(p=0.638)$. Cesarean delivery is a well-known protective factor in infants with neonatal jaundice and decreased chances of readmission because of hyperbilirubinemia due to prolonged hospital stay, hence improved monitoring, early formula supplementation, less placental transfusion and stress prior to delivery prompting induction of conjugating enzymes or metabolism of bilirubin as an oxidant ${ }^{29}$. In our study, 22 of 50 participants had cesarean deliveries, with $8(50.0 \%)$ in the MRI changes group while $14(42.0 \%)$ in the normal MRI group, although the difference between both groups was not statistically significant. Interestingly, infants born through cesarean sections had mean peak values of $283.8 \pm 54.2 \mu \mathrm{mol} / \mathrm{L}$ compared to $317.9 \pm 49.3 \mu \mathrm{mol} / \mathrm{L}$ born by spontaneous vaginal delivery and the difference between peak TSB in both groups was statistically significant $(p=0.024)$. This confirmed cesarean delivery as a protective factor of hyperbilirubinemia as previously discussed. In addition, 6 participants born by spontaneous vaginal delivery had peak TSB values $>342 \mu \mathrm{mol} / \mathrm{L}$ compared to those born by cesarean section with 6 participants in that range.

Typical magnetic resonance imaging (MRI) shows a transition of symmetrical hyper intensity in the global pallidus and thalamus earlier on T1WI (T1 Weighted Imaging) to this symmetrical hyper intensity on T2WI (T2 Weighted Imaging) indicating a poorer prognosis in acute bilirubin encephalopathy 8,19,30-31. The debate persists if lower levels of bilirubin can cause brain damage in term neonates and if different degrees of bilirubin levels correlate with different patterns of brain injury, thereby leading to a change in imaging observed ${ }^{32}$. Lesions confirmed to more rostral and dorsal-medial regions of the globus pallidus produce the greatest cognitive defect in patients ${ }^{33}$. Bilirubin-related impairment within the dorsal regions of the globus pallidus affects working memory functions, critical for a child's success ${ }^{34}$. White matter changes may be secondary to grey matter changes with changes consistent with periventricular leukomalacia, $\mathrm{PVL}^{35}$ but none of our participants had abnormal white matter abnormalities. Our study shows classical MRI changes on T1WI but its role in prognosticating poor outcomes is not clear, as we could not find a consistent association between MRI abnormalities and adverse outcomes. There was a

Page $15 / 20$ 
significant difference between participants with MRI changes, who had a mean bilirubin level of $342.5 \pm 47.6 \mu \mathrm{mol} / \mathrm{L}$ to $284.3 \pm 46.3 \mu \mathrm{mol} / \mathrm{L}$ in those without changes $(\mathrm{p}=0.000)$, with a pearson coefficient of -0.510 .There was a significant correlation between serum bilirubin levels and signal strength on magnetic resonance imaging, i.e. increased serum bilirubin and increased MRI signal intensity. ROC curve showed that bilirubin levels of $310.5 \mu \mathrm{mol}$ had true and false positive rates of $62.5 \%$ and $35.3 \%$ on MR imaging. Odds ratios when observing TSB values with $342 \mu \mathrm{mol} / \mathrm{L}$ as cut-off showed that participants with TSB $\geq 342 \mu \mathrm{mol} / \mathrm{L}$ were 12.4 times more likely of presenting with abnormal MR imaging (OR=12.4, $95 \% \mathrm{Cl}$ 2.191-70.672). Therefore, we believe that: $\mathrm{TSB} \geq 342 \mu \mathrm{mol} / \mathrm{L}$ can be used as a reference standard for testing head MRIs in children with hyperbilirubinemia. In addition, a cross-tab comparison between MRI and milestones depicts MRI as having a $66.7 \%, 70.2 \%$ sensitivity and specificity while having a 12.5\% PPV and $97.1 \%$ NPV for milestone attainment. Unfortunately such a cut-off value for MRI changes could not be established for abnormal neurodevelopment. Muen and Bannister showed that findings on imagery cannot straightforwardly explain neurodevelopmental delays ${ }^{36}$.

Among all the participants involved, 3 participants had abnormal DDST scores during the study, with 1 participant having a delay at 9 months during follow-up. Johnson observed cognitive deficits in neonates as they develop regardless of the cause of neonatal jaundice ${ }^{37}$. Some aspects of nervous system functioning and cognition in infants and children may not be apparent until much later than 3 years $^{38}$.Therefore, the effect of imaging changes in MRI on the long-term prognosis of children with hyperbilirubinemia may require longer follow-up times and increased sample size for further study.

Limitations of our retrospective cohort involve a small sample size and loss of participants during followup for various reasons. Moreover the time for follow-up was short as most neurological deficits are observed at around 2 years of age after maturation of frontal cortices and neuropsychiatric symptoms are observed much later. For example athetoid cerebral palsy or other signs of kernicterus may remain undetected by year 1 . A strength of our study was we evaluated MRI scans including DWI sequences, ABR tests in all participants and showed a cut-off TSB level for increasing sensitivity and specifity of MRI scanning.

\section{Conclusion}

1. In children with hyperbilirubinemia, with the increase of total serum bilirubin levels, the probability of abnormalities in the head magnetic resonance imaging (MRI) increased significantly $\geq 342 \mu \mathrm{mol} / \mathrm{L}$;

2. Although early MRI imaging changes cannot independently predict the outcome of early neurodevelopment in infants with hyperbilirubinemia, it is necessary to extend the follow-up regarding growth and development in children with MRI abnormalities.

\section{References}


1. Stevenson DK, Dennery PA, Hintz SR. Understanding newborn jaundice. J Perinatol. 2001;21 Suppl 1:S21-S39. doi:10.1038/sj.jp.7210628

2. Bhutani, Vinod $\mathrm{K}$ et al. "Predischarge screening for severe neonatal hyperbilirubinemia identifies infants who need phototherapy." The Journal of pediatrics vol. 162,3 (2013): 477-482.e1. doi:10.1016/j.jpeds.2012.08.022

3. Shapiro SM. Bilirubin toxicity in the developing nervous system. Pediatr Neurol. 2003;29(5):410-421. doi:10.1016/j.pediatrneurol.2003.09.011

4. Cashore WJ. The neurotoxicity of bilirubin. Clin Perinatol. 1990 Jun;17(2):437-47. PMID: 2196139.

5. Juretschke LJ. Kernicterus: still a concern. Neonatal Netw. 2005 Mar-Apr;24(2):7-19. doi: 10.1891/0730-0832.24.2.7. PMID: 15835475

6. Sarici SU. Incidence and etiology of neonatal hyperbilirubinemia. J Trop Pediatr. 2010 Apr;56(2):1289. doi: 10.1093/tropej/fmp041. Epub 2009 Jun 5. PMID: 19502601.

7. Suresh GK, Clark RE. Cost-effectiveness of strategies that are intended to prevent kernicterus in newborn infants. Pediatrics. 2004 Oct;114(4):917-24. doi: 10.1542/peds.2004-0899. PMID: 15466085.

8. Shapiro SM. Chronic bilirubin encephalopathy: diagnosis and outcome. Semin Fetal Neonatal Med. 2010 Jun;15(3):157-63. doi: 10.1016/j.siny.2009.12.004. Epub 2010 Jan 29. PMID: 20116355.

9. Sarı S, Yavuz A, Batur A, Bora A, Caksen H. Brain magnetic resonance imaging and magnetic resonance spectroscopy findings of children with kernicterus. Pol J Radiol. 2015 Feb 11;80:72-80. doi: 10.12659/PJR.892643. PMID: 25745520; PMCID: PMC4327183.

10. Haataja LH, Mercuri E, Regev R, Cowan F, Rutherford M, Dubowitz V, et al. Optimality score for the neurologic examination of the infant at 12 and 18 months of age. J Pediatr 1999;135:153-61.

11. Shelov S, Altmann TR. CDC developmental Milestone Chart. 1991. https://www.cdc.gov/ncbddd/actearly/pdf/checklists/all_checklists.pdf. (accessed on September, 23rd 2020)

12. https://doctorguidelines.com/2016/08/03/child-development-assessment-developmentalmilestones-and-denver-developmental-screening-test/ (accessed on September, 26th 2020)

13. Wolf MJ, Wolf B, Bijleveld C, Beunen G, Casaer P. The predictive value of developmental testing of extremely jaundiced African infants. Dev Med Child Neurol. 1998 Jun;40(6):405-10. PMID: 9652782.

14. Newman TB, Klebanoff MA. Neonatal hyperbilirubinemia and long-term outcome: another look at the Collaborative Perinatal Project. Pediatrics. 1993 Nov;92(5):651-7. PMID: 8414851.

15. Katar S, Akay HO, Taskesen M, Devecioglu C. Clinical and cranial magnetic resonance imaging (MRI) findings of 21 patients with serious hyperbilirubinemia. J Child Neurol. 2008 Apr;23(4):415-7. doi: 10.1177/0883073807309780. Epub 2008 Jan 8. PMID: 18182649.

16. Smitherman H, Stark AR, Bhutani VK. Early recognition of neonatal hyperbilirubinemia and its emergent management. Semin Fetal Neonatal Med. 2006 Jun;11(3):214-24. doi: 10.1016/j.siny.2006.02.002. PMID: 16603425. 
17. Slusher TM, Zamora TG, Appiah D, Stanke JU, Strand MA, Lee BW, Richardson SB, Keating EM, Siddappa AM, Olusanya BO. Burden of severe neonatal jaundice: a systematic review and metaanalysis. BMJ Paediatr Open. 2017 Nov 25;1(1):e000105. doi: 10.1136/bmjpo-2017-000105. PMID: 29637134; PMCID: PMC5862199.

18. Bhutani VK, Zipursky A, Blencowe H, Khanna R, Sgro M, Ebbesen F, Bell J, Mori R, Slusher TM, Fahmy N, Paul VK, Du L, Okolo AA, de Almeida MF, Olusanya BO, Kumar P, Cousens S, Lawn JE. Neonatal hyperbilirubinemia and Rhesus disease of the newborn: incidence and impairment estimates for 2010 at regional and global levels. Pediatr Res. 2013 Dec;74 Suppl 1(Suppl 1):86-100. doi: 10.1038/pr.2013.208. PMID: 24366465; PMCID: PMC3873706.

19. Abbey P, Kandasamy D, Naranje P. Neonatal Jaundice. Indian J Pediatr. 2019 Sep;86(9):830-841. doi: 10.1007/s12098-019-02856-0. Epub 2019 Feb 21. PMID: 30790186.

20. Gkoltsiou K, Tzoufi M, Counsell S, Rutherford M, Cowan F. Serial brain MRI and ultrasound findings: relation to gestational age, bilirubin level, neonatal neurologic status and neurodevelopmental outcome in infants at risk of kernicterus. Early Hum Dev. 2008 Dec;84(12):829-38. doi: 10.1016/j.earlhumdev.2008.09.008. Epub 2008 Oct 11. PMID: 18851903.

21. Gazzin S, Tiribelli C. Bilirubin-induced neurological damage. J Matern Fetal Neonatal Med. 2011 Oct;24 Suppl 1:154-5. doi: 10.3109/14767058.2011.607590. PMID: 21942616.

22. Rodrigues CM, Solá S, Castro RE, Laires PA, Brites D, Moura JJ. Perturbation of membrane dynamics in nerve cells as an early event during bilirubin-induced apoptosis. J Lipid Res. 2002 Jun;43(6):88594. PMID: 12032163.

23. Taoka T, Aida N, Ochi T, Takahashi Y, Akashi T, Miyasaka T, Iwamura A, Sakamoto M, Kichikawa K. Transient hyperintensity in the subthalamic nucleus and globus pallidus of newborns on T1weighted images. AJNR Am J Neuroradiol. 2011 Jun-Jul;32(6):1130-7. doi: 10.3174/ajnr.A2451. Epub 2011 Apr 21. PMID: 21511869.

24. Woodward LJ, Clark CA, Pritchard VE, Anderson PJ, Inder TE. Neonatal white matter abnormalities predict global executive function impairment in children born very preterm. Dev Neuropsychol. 2011;36(1):22-41. doi: 10.1080/87565641.2011.540530. PMID: 21253989.

25. Burke BL, Robbins JM, Bird TM, Hobbs CA, Nesmith C, Tilford JM. Trends in hospitalizations for neonatal jaundice and kernicterus in the United States, 1988-2005. Pediatrics. 2009 Feb;123(2):52432. doi: 10.1542/peds.2007-2915. PMID: 19171618.

26. Seidman DS, Paz I, Stevenson DK, Laor A, Danon YL, Gale R. Neonatal hyperbilirubinemia and physical and cognitive performance at 17 years of age. Pediatrics. 1991 Oct;88(4):828-33. PMID: 1896294.

27. Amin SB. Clinical assessment of bilirubin-induced neurotoxicity in premature infants. Semin Perinatol. 2004 Oct;28(5):340-7. doi: 10.1053/j.semperi.2004.09.005. PMID: 15686265.

28. Bergman I, Hirsch RP, Fria TJ, Shapiro SM, Holzman I, Painter MJ. Cause of hearing loss in the highrisk premature infant. J Pediatr. 1985 Jan;106(1):95-101. doi: 10.1016/s0022-3476(85)80476-5. PMID: 3965686. 
29. Golmirzaei J, Namazi S, Amiri S, Zare S, Rastikerdar N, Hesam AA, Rahami Z, Ghasemian F, Namazi SS, Paknahad A, Mahmudi F, Mahboobi H, Khorgoei T, Niknejad B, Dehghani F, Asadi S. Evaluation of attention-deficit hyperactivity disorder risk factors. Int J Pediatr. 2013;2013:953103. doi: 10.1155/2013/953103. Epub 2013 Nov 10. PMID: 24319465; PMCID: PMC3844208.

30. Assefa Neknek G, Woldemichael K, Moges A, Zewdneh Solomon D. MRI of bilirubin encephalopathy (kernicterus): A case series of 4 patients from Sub-Saharan Africa, May 2017. Radiol Case Rep. 2018 Apr 16;13(3):676-679. doi: 10.1016/j.radcr.2018.03.018. PMID: 30046365; PMCID: PMC6056755.

31. Shroff MM, Soares-Fernandes JP, Whyte $H$, Raybaud C. MR imaging for diagnostic evaluation of encephalopathy in the newborn. Radiographics. 2010 May;30(3):763-80. doi: 10.1148/rg.303095126. PMID: 20462993.

32. Soorani-Lunsing I, Woltil HA, Hadders-Algra M. Are moderate degrees of hyperbilirubinemia in healthy term neonates really safe for the brain? Pediatr Res. 2001 Dec;50(6):701-5. doi: 10.1203/00006450200112000-00012. PMID: 11726727.

33. Wisnowski JL, Panigrahy A, Painter MJ, Watchko JF. Magnetic resonance imaging of bilirubin encephalopathy: current limitations and future promise. Semin Perinatol. 2014 Nov;38(7):422-8. doi: 10.1053/j.semperi.2014.08.005. Epub 2014 Sep 27. PMID: 25267277; PMCID: PMC4250342.

34. Yan R, Han D, Ren J, Zhai Z, Zhou F, Cheng J. Diagnostic value of conventional MRI combined with DTI for neonatal hyperbilirubinemia. Pediatr Neonatol. 2018 Apr;59(2):161-167. doi:

10.1016/j.pedneo.2017.07.009. Epub 2017 Aug 3. PMID: 28864243.

35. Rutherford MA, Pennock JM, Counsell SJ, Mercuri E, Cowan FM, Dubowitz LMS, et al. Abnormal magnetic resonance signal in the internal capsule predicts poor neurodevelopmental outcome in infants with hypoxic-ischemic encephalopathy. Pediatrics 1998;102:323-8.

36. Muen WJ, Bannister CM. Hand function in subjects with spina bifida. Eur J Pediatr Surg. 1997 Dec;7 Suppl 1:18-22. doi: 10.1055/s-2008-1071203. PMID: 9497111.

37. Johnson L, Bhutani VK. The clinical syndrome of bilirubin-induced neurologic dysfunction. Semin Perinatol. 2011 Jun;35(3):101-13. doi: 10.1053/j.semperi.2011.02.003. PMID: 21641482.

38. Grimmer I, Berger-Jones K, Bührer C, Brandl U, Obladen M. Late neurological sequelae of nonhemolytic hyperbilirubinemia of healthy term neonates. Acta Paediatr. 1999 Jun;88(6):661-3. doi: 10.1080/08035259950169341. PMID: 10419253.

\section{Figures}




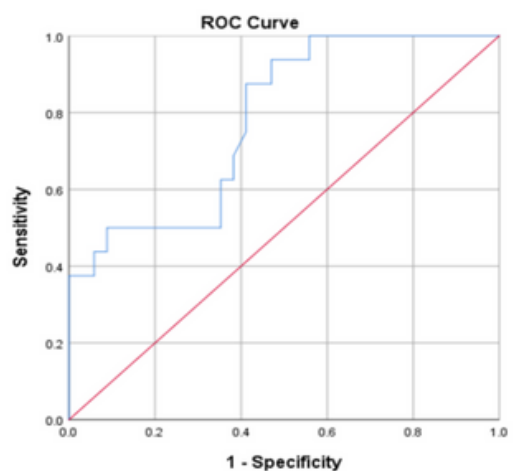

Diagonal segments are produced by ties

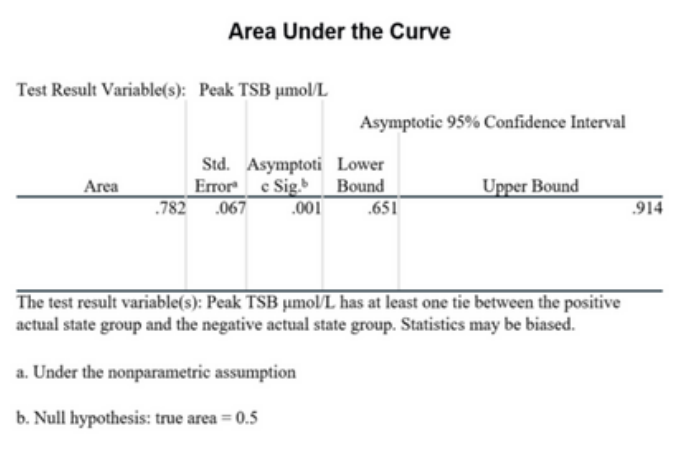

\begin{tabular}{r|r|r|r}
\hline 300.850 & .813 & .412 \\
\hline 304.550 & .750 & .412 \\
\hline 307.250 & .688 & .382 \\
\hline 309.700 & .625 & .382 \\
\hline 310.450 & .625 & .353 \\
\hline 313.400 & .563 & .353 \\
\hline 316.650 & .500 & .353 \\
\hline 317.700 & .500 & .324 \\
\hline 319.200 & .500 & .294 \\
\hline 322.250 & .500 & .265 \\
\hline 324.900 & .500 & .235
\end{tabular}

\section{OR $95 \% \mathrm{Cl}$}

Odds Ratio peak $\mathrm{TSB} \geq 342 \mu \mathrm{mol} / \mathrm{L}$

Number of cases
$12.444(2.191,70.672)$

50

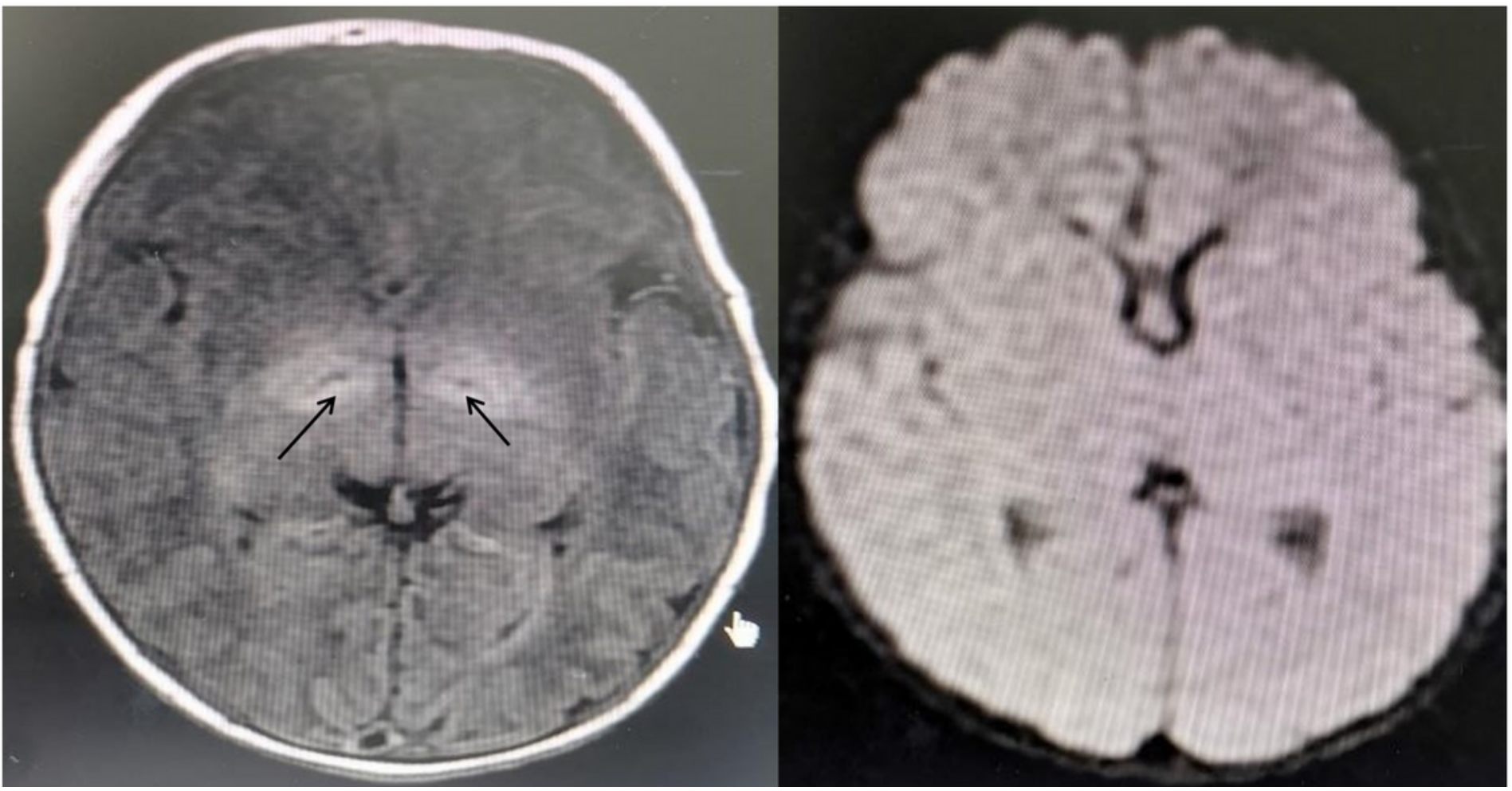

Figure 1

ROC curve and OR of peak TSB values with MR imaging and infant with abnormal follow-up at 9 month old. A 2-day old female, axial T1 FLAIR demonstrated increased intensity in global pallidus (arrows) but had a normal DWI. 9 months follow-up showed abnormal milestone attainment. 